(2) Open Access Full Text Article

\title{
Impact of an inline extracorporeal membrane oxygenation hemofilter system in neonatal acute kidney injury
}

This article was published in the following Dove Press journal:

Therapeutics and Clinical Risk Management

Mohammed Azar

Abdulrahman Alamir

Abdullah Thabet Al Qahtani

Al Mokali Khamisa

Khalid Alfakeeh

Division of Nephrology, Department of Paediatrics, King Saud bin Abdulaziz University for Health Sciences, Ministry of National Guard - Health Affairs, King Abdulaziz Medical City, Riyadh, Saudi Arabia
Correspondence: Mohammed Azar Division of Nephrology, Department of Paediatrics, King Abdulaziz Medical City, King Abdullah Specialized Children Hospital, Mail Code 1940, PO Box 22490, Riyadh II 426, Saudi Arabia

Tel +966 I I 80 I I I I ext 53524 Email shammemazar@gmail.com

\begin{abstract}
Extracorporeal membrane oxygenation (ECMO) is considered a recognized lifesaving support for patients with cardiorespiratory failure. Acute kidney injury (AKI) and fluid overload are significant morbidity factors resulting in serious complications. The inline hemofilter system (IHS) and the continuous renal replacement therapy (CRRT) machine are different methods of renal replacement therapy for patients with ECMO. IHS is the alternate, safe dialysis modality of choice because it is user-friendly, inexpensive, and efficiently removes fluid overload and renal diffusive clearance. We report on a 20-day-old male neonate with multiple congenital cardiac defects who needed venoarterial ECMO and had AKI necessitating renal replacement therapy using IHS. The patient had stable electrolyte parameters, good ultrafiltration, and efficient diffusive clearance. He was decannulated from ECMO therapy after 9 days without any related complications. Therefore, neonatal IHS is a safe and efficient alternative approach to AKI.
\end{abstract}

Keywords: extracorporeal membrane oxygenation, continuous renal replacement therapy, inline hemofilter system, cardiopulmonary bypass, acute kidney injury

\section{Introduction}

Extracorporeal membrane oxygenation (ECMO) is considered a recognized lifesaving support for patients with cardiorespiratory failure. The expected survival rate is $\sim 80 \%$ in infants compared to the survival rate of $20 \%$ in neonates. ${ }^{1-3}$ Acute kidney injury (AKI) and fluid overload are significant morbidity factors resulting in serious complications. $^{4-7}$ Studies on pediatric and neonatal ECMO have used predominantly continuous renal replacement therapy (CRRT) using the machine, but none of the studies have compared the inline hemofilter system (IHS) in relation to fluid, renal diffusive clearance, technical difficulties, episodes of clotting, cost factors, CRRT circuits, management of alarms, and CRRT nursing issues. ${ }^{8-12}$ Moreover, the aforementioned issues have a significant impact on patient outcomes. However, IHS offers a relatively easier method to efficiently dialyze the patient without any related complications. Here, we describe a neonatal patient with significant improvement in fluid overload and renal diffusive clearance in relation to neonatal IHS.

\section{Case presentation}

A 20-day-old male neonate was referred from a private hospital with a case of hypoplastic aortic arch syndrome. He was born full term via normal vaginal delivery to a primiparous mother with a birth weight of $3.4 \mathrm{~kg}$ and a normal Apgar score. Antenatal examinations including an abdominal ultrasound were completely unremarkable. 
He had no neonatal intensive care admissions, and on routine clinical examination, a cardiac murmur was detected. A cardiac echocardiogram confirmed the diagnosis of the hypoplastic aortic arch syndrome. He was started on prostaglandin E1 infusion and referred to King Abdulaziz Medical City Hospital at 15 days of age for further management. On physical examination, the patient had mild central cyanosis, soft, systolic ejection murmur at the left sternal border and high-pitched systolic murmur at the lower left sternal border. His vital signs were completely normal. Initial laboratory tests revealed that blood urea nitrogen (BUN) was $7.84 \mathrm{mg} / \mathrm{dL}$ (normal range: $7-20 \mathrm{mg} / \mathrm{dL}$ ) and serum creatinine was $0.452 \mathrm{mg} / \mathrm{dL}$ $(0.2-0.7 \mathrm{mg} / \mathrm{dL})$. Electrolytes and blood gas analyses were within normal limits. A complete blood count showed a hemoglobin level of $14.1 \mathrm{~g} / \mathrm{dL}$ (normal range: 10-12 g/dL), normal leukocytes count, and a platelet count of $742 \times 10^{9} / \mathrm{L}$ (normal range: $150-400 \times 10^{9} / \mathrm{L}$ ). There was no serological evidence of hepatitis $\mathrm{B}$ and $\mathrm{C}$ or viral infections. Blood and urine cultures were negative. Abdominal ultrasound and the chromosomal analysis including fluorescence in situ hybridization were normal. An electrocardiogram revealed the absence of Q waves in the inferior and lateral leads. An initial chest X-ray revealed mild cardiomegaly with the prominent bilateral pulmonary vasculature. Repeated cardiac echocardiogram showed a hypoplastic aortic arch, a small left ventricular outflow tract, an aortic annulus, large muscular ventricular septal defects with inlet extension, a restrictive patent foramen ovale, and a large patent ductus arteriosus.
The patient underwent surgical correction on day 20 of his life. Intraoperatively, a median sternotomy with aortic and bicaval cannulation was performed using 14 and 10 French catheters, respectively. A cardiopulmonary bypass with systemic cooling was instituted. The patent ductus arteriosus was divided, the ventricular septal defect was closed using a Gore-Tex patch, and an aortic arch reconstruction was performed using a pulmonary homograft patch. An atrial septectomy and a tricuspid valve commissuroplasty were performed. The Damus-Kaye-Stansel procedure was constructed in a side-to-side fashion and connected to the reconstructed aorta under circulatory arrest with antegrade cerebral perfusion. A $4 \mathrm{~mm}$ size Blalock-Thomas-Taussig shunt was constructed between the base of the innominate artery and the central pulmonary artery. A transesophageal echocardiogram was performed, which did not show any significant residual lesions. However, oxygen saturation declined, and the patient was placed on venoarterial ECMO (Quadrox-i pediatric; Maquet Getinge Group, Rastatt, Germany) to control the hemodynamics, allow the heart to rest, and the pulmonary vascular resistance to drop. The patient was transferred to the pediatric cardiac intensive care unit with an ECMO and ventilator support. The targeted ECMO blood flow was $70-100 \mathrm{~mL} / \mathrm{kg} / \mathrm{minute}$ with the initial flow started at $\sim 0.5 \mathrm{~L} /$ minute. The heparin dose was adjusted to maintain an activated clotting time between 180 and 220 seconds. Details of the ECMO and ventilation parameters during the hospital stay are illustrated in Table 1.

Table I Fluid, ECMO, and ventilation parameters

\begin{tabular}{|c|c|c|c|c|}
\hline & Day 2 & Day 4 & Day 6 & Day 8 \\
\hline \multicolumn{5}{|l|}{ Fluid parameters } \\
\hline Urine output (mL/kg/hour) & 0.1 & 0.2 & 0.9 & I.I \\
\hline Ultrafiltration (mL/day) & 686 & 420 & 322 & 280 \\
\hline Fluid balance ( $\mathrm{mL} /$ day) & $-320 \mathrm{~mL}$ & $-180 \mathrm{~mL}$ & $-460 \mathrm{~mL}$ & $-310 \mathrm{~mL}$ \\
\hline \multicolumn{5}{|l|}{ Ventilation parameters } \\
\hline Ventilator mode & SIMV-PC & SIMV-PC & SIMV-PC & SIMV-PC \\
\hline Peak inspiratory pressure $\left(\mathrm{cmH}_{2} \mathrm{O}\right)$ & 23 & 22 & 21 & 18 \\
\hline Positive end expiratory pressure $\left(\mathrm{cmH}_{2} \mathrm{O}\right)$ & 8 & 7 & 6 & 5 \\
\hline Inspired oxygen fraction (\%) & 50 & 40 & 35 & 30 \\
\hline \multicolumn{5}{|l|}{ Arterial blood gases } \\
\hline $\mathrm{pH}$ & 7.39 & 7.41 & 7.43 & 7.46 \\
\hline Oxygen tension $(\mathrm{mmHg})$ & 120 & 160 & 180 & 195 \\
\hline Carbon dioxide tension $(\mathrm{mmHg})$ & 47.2 & 43 & 45 & 37 \\
\hline Oxygen saturation (\%) & 91 & 93 & 92 & 95 \\
\hline \multicolumn{5}{|l|}{ ECMO parameters } \\
\hline ECMO flow/LPM & 0.5 & 0.5 & 0.4 & 0.3 \\
\hline Gas LPM & 0.4 & 0.2 & 0.2 & 0.2 \\
\hline Hemofilter & No clotting & No clotting & No clotting & No clotting \\
\hline Line pressure $(\mathrm{mmHg})$ & 189 & 175 & 185 & 190 \\
\hline ACT (seconds) & 190 & 210 & 185 & 200 \\
\hline
\end{tabular}

Abbreviations: ECMO, extracorporeal membrane oxygenation; LPM, liters per minute; ACT, activated clotting time; SIMV, synchronized intermittent mandatory ventilation; PC, pressure control. 
In addition, the patient had severe hypotension and bleeding necessitating multiple courses of fresh frozen plasma, platelets, blood transfusions, and inotropes. Postoperatively, he was noted to be anuric and clinically had significant fluid overload and poor diffusive clearance. His chest X-ray showed significant fluid overload (Figure 1A). Renal replacement therapy was initiated using an inline hemofilter (Maquet hemofilter) directly into the ECMO circuit (Figure 2). The priming volume of the hemofilter is $18 \mathrm{~mL}$ with a surface area of $0.25 \mathrm{~m}^{2}$ and designed using polypropylene fiber material. The hemofilter is incorporated after the pump and before the membrane oxygenator. After delivery through the hemofilter, the blood returned to the pre-pump limb of the circuit. Efficient ultrafiltration was balanced using a standard intravenous infusion pump connected to the effluent port of the hemofilter. The ultrafiltration was equal to the rate programmed into the infusion device. On follow-up, the patient had stable electrolyte parameters, balanced fluid removal, and efficient diffusive clearance (Table 2). He was decannulated from ECMO therapy after 9 days without any complications related to the IHS. Repeated chest X-rays showed significant improvement in relation to fluid overload (Figure 1B).

\section{Consent}

Written informed consent for the publication of this case report and any accompanying images has been obtained from the patient's father.

\section{Discussion}

We describe a neonatal ECMO patient with significant improvement in fluid overload and renal diffusive clearance in relation to IHS without any significant complications. Moreover, we performed neonatal venoarterial ECMO using IHS

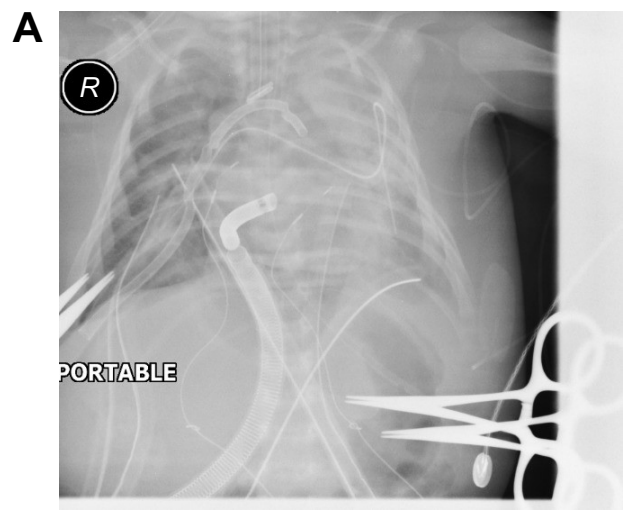

Figure I Pictures of chest radiographs during ECMO therapy. Note: (A) Two hours post ECMO and (B) 6 days post ECMO

Abbreviation: ECMO, extracorporeal membrane oxygenation. for 9 days and successfully decannulated the patient without any complications regarding clotting, technical aspects, and nursing issues. With regard to the technical aspects, combining ECMO with renal replacement therapy can be initiated in many ways. One method is by introducing the CRRT machine or a hemofilter into the ECMO circuit otherwise known as IHS. ${ }^{13-15}$ Renal replacement therapy can be conducted in a simple process in IHS, where blood for the CRRT circuit is accessed from and returned to the ECMO circuit. Moreover, the inlet and outlet of the CRRT circuit can be after or before the centrifugal pump and the membrane oxygenator depending on the medical center's experience. Another common dialysis technique is using the CRRT machine, where blood is accessed from and returned to the ECMO circuit. To avoid such complications, blood flow should be constant and strictly maintained in the CRRT machine. ${ }^{13,14}$ In addition, incorporation of a CRRT venous line into the ECMO circuit especially before the centrifuge pump may potentially trigger low pressure venous alarms in the CRRT machine and may shut down the whole ECMO circuit. Low blood flow or clots in the filter can trigger the alarms in the CRRT machine and may eventually lead to hemolysis, disseminated intravascular coagulation, or activation of the clotting cascade. ${ }^{14-17}$

However, it is postulated that CRRT using the machine is the safest mode in relation to the clotting and rupture of membranes. ${ }^{1,2,14}$ However, the priming volume of the extracorporeal circuit (ECV) for the neonate is only $18 \mathrm{~mL}$ in IHS, which eventually significantly assists the hemodynamic parameters. In contrast, CRRT with the machine using an ECV priming volume of $60 \mathrm{~mL}$ may result in detrimental consequences. It may also cause significant hemodynamic changes in the ECMO parameters especially in neonates who require multiple inotropes.

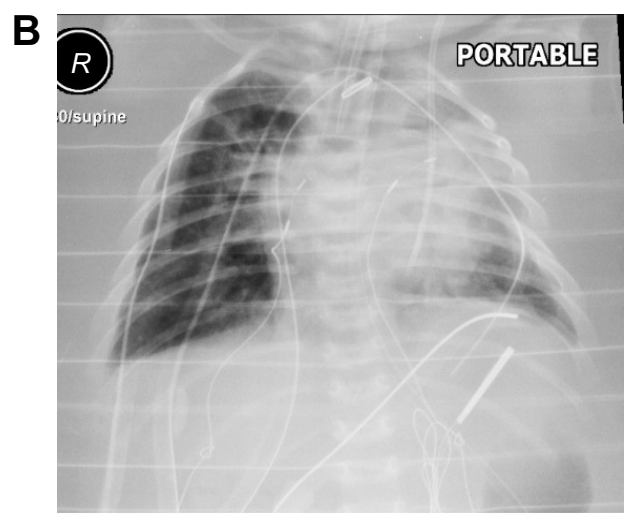




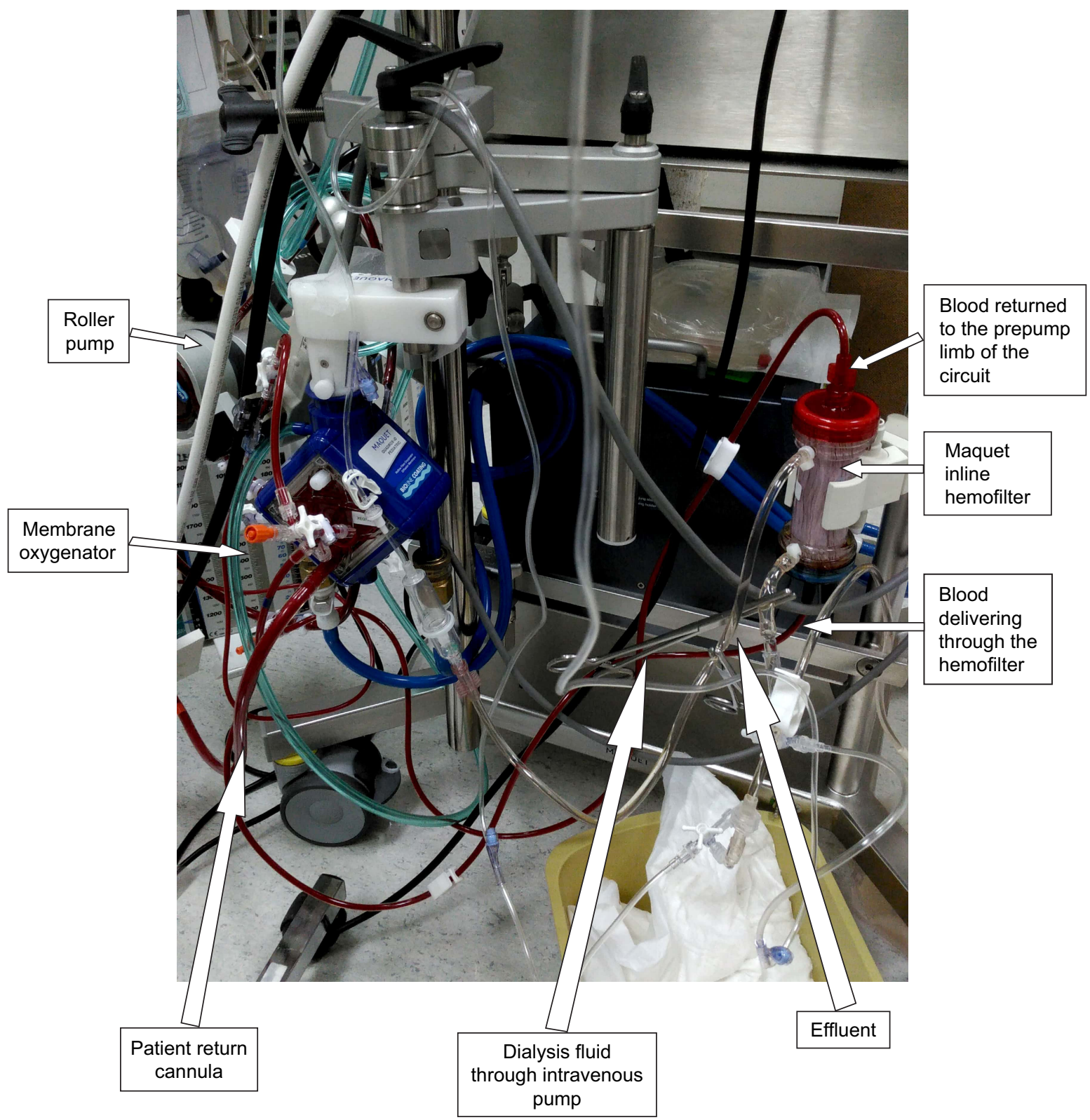

Figure 2 ECMO circuit with an inline hemofilter system.

Abbreviation: ECMO, extracorporeal membrane oxygenation.

Moreover, using a CRRT machine in the ECMO circuit requires frequent alarm monitoring, circuit changes, and carries an additional burden for the CRRT nurses and significant costs for the parents. In contrast, IHS may provide an easy and inexpensive choice of modality and significantly reduces the cost burden for the parents. IHS can potentially remove not only the fluid but also the solute clearance as clearly demonstrated in our case. Diffusive clearance and fluid overload are well managed using countercurrent dialysis fluid through an intravenous infusion pump connected to the effluent port of the filter., ${ }^{1,14}$

Convective clearance can also be achieved by using replacement fluid directly through the ECMO circuit. ${ }^{13,14}$
Newer fiber characteristics of the ECMO hemofilter are considerably effective for removing fluids and toxins as demonstrated in our case. Although the maximum ultrafiltration rate is limited in both the intravenous infusion pumps and filter, in neonates, it is highly uncommon to take fluids $>1 \mathrm{~L} /$ hour. Moreover, the frequency of clotting depends more on the blood flow and heparin dosage rather than the type of modality of dialysis. To our knowledge, no studies have correlated CRRT with IHS and with the machine, especially in relation to clotting, fluid overload, and clearance.

AKI in our patient was likely related to decreased perfusion to the kidneys secondary to poor oxygen saturation during surgery, which in turn may have resulted in acute 
Table 2 Lab monitoring on pre- and postoperative days

\begin{tabular}{|c|c|c|c|c|c|c|c|c|}
\hline \multirow[t]{2}{*}{ Parameters } & \multirow{2}{*}{$\begin{array}{l}\text { Preop } \\
\text { day }\end{array}$} & \multicolumn{7}{|c|}{ Postoperative day } \\
\hline & & Day 0 & Day I & Day 2 & Day 3 & Day 4 & Day 5 & Day 6 \\
\hline $\mathrm{Hb}(\mathrm{g} / \mathrm{dL})$ & 9.3 & 10.2 & 10.3 & 9.6 & 9.8 & 10.1 & 9.4 & 10.4 \\
\hline WBC $\left(\times 10^{9} / L\right)$ & 6.5 & 5.5 & 7.2 & 6.6 & 8.8 & 7.9 & 6.7 & 5.6 \\
\hline Platelets $\left(\times 10^{9} / \mathrm{L}\right)$ & 222 & 165 & 166 & 186 & 192 & 222 & 242 & 222 \\
\hline Sodium (mmol/L) & 138 & 135 & 137 & 138 & 137 & 136 & 134 & 139 \\
\hline Potassium (mmol/L) & 4.9 & 6.1 & 4.3 & 3.4 & 3.8 & 3.9 & 3.3 & 3.2 \\
\hline Bicarbonate (mmol/L) & 22 & 16 & 15 & 17 & 18 & 20 & 22 & 23 \\
\hline Blood urea nitrogen $(\mathrm{mg} / \mathrm{dL})$ & 7.84 & 42 & 30.8 & 29.4 & 27.4 & 26.8 & 25.7 & 23.8 \\
\hline Creatinine (mg/dL) & 0.452 & 1.470 & 1.08 & 0.99 & 0.859 & 0.83 & 0.803 & 0.81 \\
\hline LDH (U/L) & 233 & & 263 & 222 & - & - & 265 & - \\
\hline Calcium (mmol/L) & 2.4 & 2.3 & 2.5 & 2.25 & 2.56 & 2.46 & 2.47 & 2.3 \\
\hline Phosphate (mmol/L) & 1.8 & 1.5 & 1.4 & 1.65 & 1.2 & 1.4 & 1.1 & 1.3 \\
\hline Uric acid $(\mu \mathrm{mol} / \mathrm{L})$ & 220 & 469 & 210 & 215 & 202 & 196 & 186 & 188 \\
\hline Lactate $(\mathrm{mmol} / \mathrm{L})$ & 5.2 & 13.6 & 11.2 & 8.2 & 5.3 & 3.6 & 2.1 & 1.8 \\
\hline AST/ALT (U/L) & $12 / 14$ & $16 / 18$ & $19 / 22$ & $17 / 25$ & $15 / 22$ & $14 / 23$ & $17 / 22$ & $19 / 26$ \\
\hline
\end{tabular}

Abbreviations: preop, preoperative; Hb, hemoglobin; WBC, white blood cell count; LDH, lactate dehydrogenase; AST, aspartate aminotransferase; ALT, alanine aminotransferase.

tubular necrosis. Despite the good fluid challenges and boluses, our patient had significant oliguria and poor solute clearance and recovered only after a week. The pathophysiological process of AKI during ECMO therapy is not well understood; however, hormonal factors are significantly reduced in patients maintained with ECMO therapy, which can eventually lead to failure in renal homeostasis. In addition, inflammation induced by disease involving heart and lungs may have pronounced effects on the kidneys and can progress to $\mathrm{AKI} .{ }^{1,4}$ Patients requiring CRRT especially from AKI have a minimal survival rate of $17 \%$. In addition, CRRT is an additional burden and risk factor for ECMO therapy. ${ }^{1,2}$

\section{Conclusion}

For neonatal patients who have hemodynamic compromise and AKI, using renal replacement therapy with IHS may be more beneficial rather than using the machine; however, randomized studies should be conducted to compare the efficiency of different dialysis modalities particularly in relation to hemodynamics, cost burdens, clotting frequencies, and morbidity rates.

\section{Acknowledgment}

The authors would like to acknowledge our perfusionist Bader for the support and input in relation to the ECMO therapy.

\section{Disclosure}

The authors report no conflicts of interest in this work.

\section{References}

1. Askenazi DJ, Selewski DT, Paden ML, et al. Renal replacement therapy in critically ill patients receiving extracorporeal membrane oxygenation. Clin J Am Soc Nephrol. 2012;7(8):1328-1336.
2. Chen H, Yu RG, Yin NN, Zhou JX. Combination of extracorporeal membrane oxygenation and continuous renal replacement therapy in critically ill patients: a systematic review. Crit Care. 2014; 18(6):675.

3. Williams DC, Turi JL, Hornik CP, et al. Circuit oxygenator contributes to extracorporeal membrane oxygenation-induced hemolysis. ASAIOJ. 2015;61(2):190-195.

4. Smith AH, Hardison DC, Worden CR, Fleming GM, Taylor MB. Acute renal failure during extracorporeal support in the pediatric cardiac patient. ASAIO J. 2009;55(4):412-416.

5. Lin CY, Chen YC, Tsai FC, et al. RIFLE classification is predictive of short-term prognosis in critically ill patients with acute renal failure supported by extracorporeal membrane oxygenation. Nephrol Dial Transplant. 2006;21(10):2867-2873.

6. Yan X, Jia S, Meng X, et al. Acute kidney injury in adult postcardiotomy patients with extracorporeal membrane oxygenation: evaluation of the RIFLE classification and the Acute Kidney Injury Network criteria. Eur J Cardiothorac Surg. 2010;37(2):334-338.

7. Askenazi DJ, Ambalavanan N, Hamilton K, et al. Acute kidney injury and renal replacement therapy independently predict mortality in neonatal and pediatric noncardiac patients on extracorporeal membrane oxygenation. Pediatr Crit Care Med. 2011;12(1):e1-e6.

8. Keckler SJ, Laituri CA, Ostlie DJ, St Peter SD. A review of venovenous and venoarterial extracorporeal membrane oxygenation in neonates and children. Eur J Pediatr Surg. 2010;20(1):1-4.

9. Ford JW. Neonatal ECMO: current controversies and trends. Neonatal Netw. 2006;25(4):229-238.

10. Kim ES, Stolar CJ. ECMO in the newborn. Am J Perinatol. 2000;17(7): 345-356.

11. Yeo AS, Chong JH, Tan TH, Ng AS, Rajadurai VS, Chan YH. Neonatal and paediatric extracorporeal membrane oxygenation (ECMO) in a single Asian tertiary centre. Ann Acad Med Singapore. 2014;43(7): 355-361.

12. Cavagnaro F, Kattan J, Godoy L, et al. Continuous renal replacement therapy in neonates and young infants during extracorporeal membrane oxygenation. Int J Artif Organs. 2007;30(3):220-226.

13. Santiago MJ, Sanchez A, Lopez-Herce J, et al. The use of continuous renal replacement therapy in series with extracorporeal membrane oxygenation. Kidney Int. 2009;76(12):1289-1292.

14. Seczynska B, Krolikowski W, Nowak I, Jankowski M, Szułdrzynski K, Szczeklik W. Continuous renal replacement therapy during extracorporeal membrane oxygenation in patients treated in medical intensive care unit: technical considerations. Ther Apher Dial. 2014;18(6): $523-534$. 
15. Ricci Z, Morelli S, Vitale V, Di Chiara L, Cruz D, Picardo S. Management of fluid balance in continuous renal replacement therapy: technical evaluation in the pediatric setting. Int J Artif Organs. 2007;30(10): 896-901.

16. Urlesberger B, Zobel G, Zenz W, et al. Activation of the clotting system during extracorporeal membrane oxygenation in term newborn infants. J Pediatr. 1996;129(2):264-268.
17. Betrus C, Remenapp R, Charpie J, et al. Enhanced hemolysis in pediatric patients requiring extracorporeal membrane oxygenation and continuous renal replacement therapy. Ann Thorac Cardiovasc Surg. 2007; 13(6):378-383.

\section{Publish your work in this journal}

Therapeutics and Clinical Risk Management is an international, peerreviewed journal of clinical therapeutics and risk management, focusing on concise rapid reporting of clinical studies in all therapeutic areas, outcomes, safety, and programs for the effective, safe, and sustained use of medicines. This journal is indexed on PubMed Central, CAS,
EMBase, Scopus and the Elsevier Bibliographic databases. The manuscript management system is completely online and includes a very quick and fair peer-review system, which is all easy to use. Visit http://www.dovepress.com/testimonials.php to read real quotes from published authors.

Submit your manuscript here: http://www.dovepress.com/therapeutics-and-clinical-risk-management-journal 